\title{
Transactional Approach in Assessment of Operational Performance of Companies in Transport Infrastructure
}

\author{
Valery Dubrovsky $^{1}$ (D), Natalya Yaroshevich $^{1}$ (D), Evgeny Kuzmin ${ }^{2}$ iD \\ ${ }^{1}$ Ural State University of Economics (Russia) \\ ${ }^{2}$ Institute of Economics of the Urals Branch of the Russian Academy of Sciences (Russia) \\ dubr@usue.ru,_iarnat@mail.ru,knzminea@gmail.com
}

Received: October 2015

Accepted: February 2016

\section{Abstract:}

Purpose: Offer an alternative method to assess operational performance of companies in transport infrastructure of a region by making a comparison between transaction costs. The method is supposed to be a cross-functional and possibly applied to an analysis of economic entities of a different order (country, region, sector, companies) while evaluating "viscosity" / complexity of the outside and the inside.

Design/methodology/approach: The paper includes an analysis of various methodological approaches to assess a development level of the transport infrastructure in a region. Within the author's approach and for purposed of the research, an index of transaction capacity or the transactionalness index is proposed, which determines a level of transaction costs calculated against the cost of production and revenue. The approach is piloted using the region-wise consolidated financial data of companies involved in the Russian transport infrastructure for $2005 / 2013$.

Findings: The proposed alternative way to measure corporate operating efficiency has proved its academic consistency. A specific comparison between the transaction costs using the transactionalness index allows first to identify companies or regions/sectors, where there is excess complexity of economical communication in bargaining. Secondly, the index does not only point out indirectly to a degree of development in the institutional environment, but also the 
infrastructure (the transport one in the example given). Third, the transactionalness level may say of uncertainty and risks. As an addition to theoretical and methodological aspects of transaction costs, the authors justify an approach to their size estimation, as well as their differentiation dividing them into two groups: those of a natural type and a background type. In a course of their discussion, the authors have concluded that there are such transaction costs in place, which are standard in a manner of speaking.

Originality/value: There is a discussion whether it is scientifically reasonable to use an index of transactionalness. There are reasons for applicability of the alternative approach to assess operational performance of companies in transport infrastructure as an indicative criterion of favouring external conditions to execute exchange transactions. According to the authors, a high level of transactionalness is associated with a low development level of transport infrastructure in a region. This says that their competitiveness is specifically less.

Keywords: transactionalness, transport infrastructure, transaction costs, performance of transport infrastructure

\section{Introduction}

With its leading position in manufacturing and social subsystems of a regional infrastructure, transportation, along with economic relations that maintain its functioning, is the most powerful factor in a distribution of productive forces. Its availability considerably contributes into an achieved image and a living standard, being a necessary condition for business development, an assessment of a potential and involvement of economic actors within the economic process and an attribute of competitive advantages in a region.

The meaning of transport and corporate operating efficiency in the sector are particularly obvious in geographically extensive regions. Russia is a representative example, where a distance between contractors may serve as a factor that generates a closed economic loop and independent regional subsystems (Krylov \& Runova, 2008). It is getting evident that the homogenous economic system is only possible to be achieved when there is efficient communication between all its constituents. It is the transport infrastructure that defines conditions for a free circulation of material goods, labour and other resources (Molle, 2004). At the same time, a number of features, such as a territorial extension of Russia, its resource base remote from places of processing and production, as well as time to move commodity 
flows predefine available challenges that impose quite a specific list of requirements to development of the transport infrastructure.

Simplicity, ease and a speed in cargo handling are the most clear and obviously essential characteristics of capacities in the transport infrastructure in a region. Their improvement, on the one hand, contributes into a potential for an economic growth in a region. On the other hand, this is a factor, which decreases a significant volume of overhead. Ultimately, a smoothly running operation of the regional transport infrastructure should result in uninterrupted processes of reproduction to ensure a significant speed-up in the capital turnover. Such a conclusion is anyway suggested by the logic of a causal analysis.

A process of making the transport infrastructure of a region cannot do without tools to assess its efficiency. It becomes important here to understand a multidimensional nature of the transport performance effect as such. Absolute and relative indicators describing a length of communication arteries (Jinlong, 2003; Haywood, 2012), the cargo turnover (Zhang, 2009), location density for roadside service facilities (Thrall, 2002; Ray, Weir \& Hopp, 2003) etc. cannot fully describe a contribution and an impact of the transport infrastructure on other economic sectors. This evidently points out to a scientific problem of the research, a meaning of which comes down to a search for cross functional tools to assess a quality of the transport infrastructure (as a research object), as well as a sort of 'viscosity' of the economic space. The latter is for the most part relevant to institutional constraints - in incompleteness of rules, standards and mechanisms of proper behaviour (institutional protocol), as well as complexity of communication, bargaining and formalizing terms of a deal.

A search for a solution to the mentioned scientific problem is in line with development of the author's approach, based on findings from a critical discussion of existing ways and concepts. At the same time, it can be summarized from the review of literature that in traditional approaches to the economic analysis, there have been accepted a practice to express an assessment of a current condition of the transport infrastructure with indicators of the economic losses or the economic damage (Voicu \& Lahr, 2012). This evaluation is complemented with a long line of qualitative descriptors, usually showing that there are significant difficulties in infrastructure for all modes of transportation, mentioned by Sharon (2014) and Lahiri and Yao (2004). The approach of such kind let us estimate the transport infrastructure in a quite one-sided way. This means that there is a methodological gap in the theory of the question where a sufficient solution to the problem would be an approved performance criterion different from a traditional.

In this context, as a possible solution to the problem, the authors propose for an academic discussion to apply cross functional index of transactionalness (see more in Kuzmin, 2013) to measure performance in a regional transport infrastructure. The index, although presenting a cumulative influence of conditions that describe objective difficulties in business (i.e. exchange transactions), is in one or another way perceived by economic agents in a region as restrictions for operating optimization, in its quantitative 
estimates it describes a potential of commercial benefits from the transport infrastructure development. Therefore, among the other things, it can serve as a technique to ground needs of a region (area) in new or development of available transport infrastructure facilities.

The layout of the research is subject to the mentioned goals and objectives. The review of literature section has refined approaches to assess the transport infrastructure. The research methods involve such questions, as calculating transaction costs and their possible application as an efficiency criterion. The empirical section is based on an analysis of the transactionalness level for companies involved in transport infrastructure in Russia for the last eight years until 2013. Based on the research findings, respective conclusions have been made.

\section{Literature Review}

\subsection{Approaches to Assessment of Transport Infrastructure}

To avoid ambiguity in this research, we should say that the transport infrastructure in a region refers to a set of conditions for an exchange and a turnover of goods that determine performance in activities of economic agents in a local economic system. At the same time, this means that the conditions created for exchange transactions also determine a nature of administrative decisions regarding a choice of directions and a way of distribution.

Modern economics distinguishes several directions to evaluate the regional transport infrastructure. They are those arbitrarily designated as industry-specific, territorial and systemic.

The industry-specific approach is usually based on understanding the transport infrastructure as a sophisticated system. Therefore, estimates come from a need, first, to identify a condition of each individual subsystem within the transport infrastructure in terms of its compliance with the requirements set (in one way or another) for the whole economic system (Jochimsen, 1966). Under this approach, three components of the transport infrastructure are distinguished: tangible, institutional and personal.

Following the same principle of a multidimensional view of a regional transport infrastructure, Russian economists Stakhanov and Platonov (1993) think that production (roads, channels, ports, warehouses, communication systems, etc.), social, financial, information and commercial components are appraisal objects. Obviously, a distinguishing characteristic of this approach is multiplicity of distinct assessments of transport infrastructure condition. Moreover, in some cases they require their integration. However, there has been no known positive result from a search for a way of integration, confirmed with any wider application. Other researchers go away from the multi-dimensional idea of the transport infrastructure, 
giving specific models to evaluate its condition. Thus, Murzaev (2013) gives reasons that it is reasonable to apply as an evaluation tool the balance model of transport infrastructure development within the meso-level economic system of the following form:

$$
\sum P_{r i t}(1 /(1+r))_{i} \leftrightarrow \Sigma I N V_{i n f}^{*}(1+r)_{i}
$$

where $r$ - discount rate used to assess transport infrastructure projects in a region, a share; $i$ - serial number of a year when a relevant infrastructure project for which a calculation is made was completed; $P_{\text {rit }}$ - total balanced financial result from activities of transportation and logistics providers in a region resulting from a use of infrastructure facilities; $I N V_{i n f}$ - total initial investments in regional transport subsystems to implement a project related to infrastructure development.

On the other hand, within the considered approach they propose a large number of simple techniques to evaluate the transport infrastructure by its target purpose as a criterion. An example might be the transport service index (TSI) according to Lahiri and Yao (2004). Calculations made with TSI show a monthly change to volumes of services rendered by cargo and passenger carriers. However, an estimate received in such a way, cannot be considered economics-specific fully, as it does not imply an answer to a question of a price and a quality of an achieved result.

The second approach, territorial, is in the context of studies in location of industries within an economic system of a region (see more in Lipiec, Pulyarkin \& Schlichter, 1999), which is among other things described with a development level of the transport infrastructure. This approach, the most common in economics, is amazing owing to its valuation parameters. Among them, for example, according to Engel, there are an indicator of transport networks density. Uspensky mentions a ratio of a network length to a geometrical average of its land area, population, and a total weight of cargos handled within this freight network. Protodyakova mentions a relationship between a rate of supply with lines of communication and network traffic density, taking into account average density of population and a national level of industrial development.

It is worth saying that the territorial aspect in estimates of the transport infrastructure development is usually present as a characteristic of conditions for an economic growth. A good example might be Sharon J. Erenburg (2014) with a model saying that all countries in terms of development conditions are divided into three categories. They are so-called overloaded, intermediate and lagging-behind countries. There is another example, paper by Voicu \& Lahr (2012) that proposes to use indices to measure transport costs as a tool to assess conditions to make business in different countries. With their help, the authors define countries with more or less favourable conditions in terms of the transport infrastructure. 
Distinguishing of the third approach to assess the transport infrastructure is because other abovementioned approaches do not take into account a synergistic effect of the regional transport infrastructure. Therefore, a starting point in the systemic approach is an idea of the transport infrastructure as a "growing point".

Gabriel, Mattey and Wascher (2013) agree with this view. They say that a quality of life in a country improves and a standard of living increases if government expenses are mainly focused on a growth in social welfare through the transport infrastructure development. Nadiri (1996) has the same ideas when illustrates an approach to an assessment of the transport infrastructure with macroeconomic models, functionally binding economy-wide effects and transportation activities. For more details on the effect of the development level in the transport infrastructure upon a region's economics, see Sue Wing (2007) and Lakshmanan (2011).

The presented review makes quite an obvious conclusion that there are ambiguous solutions to an objective of the transport infrastructure evaluation. Although we cannot deny the fact that in some cases, a use of a certain approach depends on a nature of a set research goal. However, let us point out to a common disadvantage for all the above-mentioned approaches. None of them let us evaluate a quality, with which the transport infrastructure performs its principal systemic function, i.e. providing economic agents with necessary conditions for an efficient exchange. Bearing in mind that they are those conditions that set a level of transaction costs, the authors, among other things, propose an alternative approach to their measurement.

\subsection{Transaction Costs as Parameter to Assess Economic Systems}

Ideas on a nature and a content of transaction costs are highly heterogeneous, but at the same time, they have common fundamental statements. Many researchers have been involved in studies of transaction costs and their impact on enterprise activities. Among them, there are founders of scholarly traditions in neoclassical economics, such as Coase, Arrow (1969), Stigler (1972), Eggertsson (1990), Milgrom \& Roberts (1992), etc. In the Russian economics, transaction costs have been mainly explored since the end of the $20^{\text {th }}$ century. Later, they were developing together with a general trend in the theory and practice of the issue. Their fundamental provisions are presented in Popov (2011a, 2011b), Shastitko (1997), Burkov (1999), Arhiereev (2000), Kuz'minov, Bendukidze and Yudkevich (2006), Serebryakov (2007), Syrov (2008), Balsevich, Yudkevich and Podkolzina (2009).

A calculation of transaction costs in the economic system is a known methodological challenge. In this regard, it is necessary to justify the approach introducing the author's view of both essential characteristics 
of the transaction costs phenomenon, and a method to evaluate it. To solve the set objective, let us refer to findings from the most authoritative papers.

For example, in approaches to an assessment of transaction costs, Wallis \& North (1986) use a technique to separate a share of transaction sectors in economics from a structure of the gross domestic product going in two directions, i.e. non-transaction and transaction industries.

In estimates of transaction costs, Kokorev (1996) used data on a turnover in the Russian economics as a whole, also taking into consideration overhead costs of companies.

In his definition of transaction costs, Radaev (1999) took into account the 'costs for an entry and an exit from a market, an access to resources, a transmission specification and protection of ownship rights, establishment and maintenance of business relationship'.

To solve a problem of transaction costs calculation, Popov (2011a, 2011b) refers to the Tax Code of the Russian Federation, he identifies them as a part of the costs not included in calculations of a taxable base by the income tax. In his research, each kind of transaction costs is associated with operation of an economic institution serving as a specific attribute to make a classification of expenditures. Auzan (2006) is much more specific with a tax nature of a share in transaction costs, speaking of taxes due to the government as a necessity that lets us solve questions on specification and protection of property rights.

The context of the latter statement is interesting as it allows to assume a use of taxes mobilized by the government, for example, to make and develop elements in the logistics infrastructure (transport, commercial, industrial), designed to create conditions to reduce by-transaction costs. On the other hand, taxation imposes a fiscal burden on companies and organizations, leading to an increased and explicit transaction costs.

Justification of conditions and factors that determine the dynamics and a nature of changes to transaction costs is the second major problem in neo-classical concepts of transaction costs theory. Approaches to make the transactional function are very diverse and cited in many papers, in particular in Jabusch (1985), Heinesen (1992), Demchuk (2002), Popov (2009), etc. The function may be bent in or convex, as Demchuk points out, depending on observed negative or positive effects of an exchange scale. It should be said that changes to transaction costs, explained with the dynamics and scales of operations with assets are perceived as realistic.

However, the most researchers recognise a role of a transactional function as a basis to describe a price mechanism coordinating relationships between economic agents. In addition, at the same time, it allows us to solve a problem of a search for an optimal balance between the supply function for a certain amount of the mass of commodities and the function of a demand for a volume of resources required for 
its production. Pricing against the mentioned functions of the supply and the demand implies making a transaction. That is, the transaction is executed, if in an agreed way they achieve a certain optimum value in the price difference between a volume of the mass of commodities and a volume of resources to produce it.

Further detailization for the function of transaction costs is unlikely to add anything to particular complexity in solving the optimization problem for transaction costs. Its criterion should be understood as increasing performance of the economic mechanism, when overall utility of goods consumption (produced goods and services) achieves its acceptable levels. It is when seemingly there the relatively stable and balanced economic system is provided. Nevertheless, risks of economic agents in each case, say, will depend on changes to transaction costs. It means whether they increase or decrease per further unit of effect (goods and services).

Taking into account that transaction costs are commonly understood as "costs that accompany a relationship between economic agents" (Kuz'minov et al., 2006), an arithmetic approach of all kinds to an assessment of transaction costs is conventionally applicable. Firstly, because of an available objective crowd of transactions not shown in any reports and a large number of hidden exchange transactions (including those executed in the shadow market). Secondly, and the most important, the wider a scope of the economic activity of a company is, the more uncertain a boarder is, which separates transformation from transaction costs. Wallis and North (1986) quite precisely noticed a source for this difficulty. In their research, they say that, "the highest conceptual difficulty appears with those transactions that occur within a company". (Wallis \& North, 1986) Thus, in its content, the transaction costs assessment does not only include the measurement problem as such, but also transaction costs observability.

\subsection{Authors' View on Solution to Problem of Transaction Costs Estimates}

The authors come from the fact that if there is a running company (that functions as a full unit coordinating economic activities); a level of its transaction costs depends on conditions, under which any exchange transactions are executed. Moreover, these conditions should be taken into account in making management decisions that define a particular line of corporate behaviour in its relationships with contractors.

Each industry and every company therein have their own and distinctive level of transaction costs. Maher (1997) indirectly mentions this phenomenon, although the most significant finding from her research is an empirical evidence of a special meaning of the market structure in process when transaction costs are made. Popov follows the same rationale and establishes a connection between the transactional function 
and parameters of the economic environment, in which a transaction takes place. Besides, we can say that various industries (economic activities) and regions have distinct, natural or underlying levels of transaction costs. Concepts of "underlying" or "natural" level of transaction costs were introduced to describe with much comprehensiveness properties of the transactionalness phenomenon. However, in case readers are interested in this aspect, first, known limitations to this paper do not allow an extended definition for the content of both underlying and natural levels of transaction costs. Secondly, if these concepts seemingly really deserve some attention, you are advised to refer to the authors' paper, containing statement that is more detailed and a solution for such an academic challenge.

Natural refers to a standard to a certain extent level of transaction costs incurred by companies of the same economic activity or companies located within the same region. However, companies in the same industry (economic activity) from different regions will have a distinct individual level of transaction costs. In addition, in virtue of specifics of available regional factors and terms, under which the economic activity is executed, there will be observed the same trend. The underlying level of transaction costs of companies in the same branch and the same structure of production will be significantly different. It is the underlying level of transaction costs, which if not in time of incorporation, then later allows us answering the following questions. How and why did a company choose a given location, and hence its immediate environment, defined these volumes and production methods, as well as in some cases, terms of consumption for manufactured products and services? Accordingly, how and why did a company set for itself (company) the highest acceptable risk in exchange operations with other economic agents?

Then a range of deviations as a difference between actual (individual for each company and dependent on a variety of administrative decisions regarding a behaviour of a company in its relations with contractors) and natural (standard, predefined with relatively unchanged, but perfect living conditions of a company) levels of transaction costs will be a basis to estimate their (deviations) admissible intervals. At the same time, a necessary precondition to solve the problem is a search for a top-level of transaction costs, when we do not go beyond it and when an impact of conditions might be estimated as generally favourable to run a company.

Thus, the problem is not the indispensable transaction costs, but their available normal value, designated by us as a natural or underlying level. This leads to a conclusion on a need in rationing transaction costs, more precisely, a search for their normal level to justify a criterion of measured living conditions of a company. Although in the real life, the problem gets more complex than it seems at the first glance. As a research on various concepts has shown, with regard to a solution to a problem of cost rationing, there is neither shared approach to a definition of the 'standard', nor satisfactory formalization of an assessment as such for a standard level of transaction costs. 
Researchers usually apply an accepted conceptual apparatus, confirming legitimacy of the available term of "standard transaction costs" (or "standard" as an option). However, they do not disclose a technique or an approach to estimate them. Here we may refer to Davidson (2002) ("standard transaction costs") and Harris (2003). The latter connects transaction costs with the price difference between the supply and the demand. Therefore, they are understood as costs that offset the standard expensed for making business. We may also refer to Shcherbinin (2011), who proposed to control transaction costs with a dynamic normal estimated against a number of indicators not accounted in reporting forms.

From our point of view, as transaction costs in general are caused by (exchange transactions) expenses, a solution to the problem of transaction costs standardization, obviously, lies in a field of exchange operations and is defined with categories that describe them. Further, taking into account indispensability in transaction costs in the exchange economics environment, a search for their normal level should, however, be related to an idea of perfect conditions to implement administrative decisions in the framework of certain plans and programs aimed at making a desired market status of a company. In other words, even in the perfect world of planning and implementing activities, any company incurs transaction costs. Herewith, one of their components, costs at a normal level, are always less than a total actual value. Such a situation is similar to a case described as a result of an imperfect valid economic mechanism compared to theoretical concepts. Finally, there is reason to say that reasons for variances between actual and standard values of transaction costs, will be always unique. But obviously, dependent on specifics of a corporate economic activity, as well as an area of its location.

Summarizing all the above-mentioned, let us argue the following. Transaction costs are costs in the open economics. Multiple contractors incur them and therefore they include both the costs for maintaining direct and a reverse links between them (contractors), and recording costs ("storage") for these interactions. In this way we, anyway, understand a reason to offer a technique to calculate transaction costs, even without using a typology of such costs. The authors only perceive a typology or classification of transaction costs in terms of theoretical systematization, whereas classifications known in practice (e.g. see Milgrom \& Robert, 1992; Eggertsson, 1990; etc.) due to complexity in accurate measuring for each type of transaction costs, make it difficult to make an evaluation model to define a level, at which conditions favour business. At the same time, a detailed and accurate calculation of an amount of costs is only necessary in case of an analysis of their structure, a development of a target managerial decision. 


\section{Methods}

\subsection{Estimating Transaction Costs}

According to the authors, theoretically, for any level of the economic system, in estimates of transaction costs, it would be desirable to use the same indicators. However, an obstacle here is a general case of relationships between contractors seen in a macro-economic aspect, as a need appears to solve a problem of double counting in cases when transaction costs in their nature incurred by an economic agent is partially a market revenue for other agents. It is quite natural in conditions of the so-called "turnover closed-loop cycle", when a crowd of production and economic relations between contactors is implemented as a line of processes to exchange initial transaction costs in their part for real economic benefits. Then, if an assessment of transaction costs for a separate economic agent may have a double form, we may reasonably assume that an estimate of actual transaction costs when there is no turnover closed-looped cycle is independent. In these circumstances, it seems reasonable to a certain extent and in an economic sense to propose estimating transaction costs connected to the economic system of contractors by deducing the profit and production cost from a total revenue of an agent (obtained difference, though with certain loopholes, includes marketing charges and business management cost), followed by all the results summed up. Undoubtedly, such an approach to an evaluation does not only need an essential refinement, but also requires many assumptions like, for instance, those that follow.

First. Exchange transactions of all economic agents in an area are closed in a single economic system and mediated by relationships with elements of a certain (local, regional) transport infrastructure. Its maturity is nothing else but a set of external and internal circumstances that are always perceived by those who make principal management decisions. Following implementation of such decisions creates preconditions for a company to achieve a certain level of transaction costs relative to underlying ones. So, benefits from the advanced infrastructure used appropriately in management decisions potentially influence different projects of a company to be successful. At the same time, it should be expected that a level of transaction costs of a company will decline with a trend to reach its threshold in number, i.e. a level of underlying costs.

Second. There is no problem of a cumulative effect that occurs when we add transaction costs of each pair of agents interacting in exchange transactions. In other words, every economic agent is autonomous; therefore, there is no problem of accounting so-called intermediate consumption of transaction costs.

Third. Taxes, paid to the government by economic agents, undoubtedly include transaction costs, a course for which is required specification and protection of property rights. 
One should also keep in mind other assumptions established in the research. Under these conditions, a mathematical equation of an evaluation approach can be separately represented as follows:

$$
T C_{i}=C C_{i}+M C_{i}+T p_{i} \text { or } T C_{i}=C C_{i}+M C_{i}+P_{i} \times T,
$$

where $T C_{i}$ - transaction costs of the $i_{-}$th enterprise or organization; $C C_{i}-$ selling expenses; $M C_{i}-$ administrative expenses $i$; $T p_{i}$ - income tax; $P_{i}$ - profit before tax; $T$ - income tax rate.

In the given equation (2), an enterprise (organization) is seen as a separate business unit or a separate economic entity that has to occur certain costs for exchange transactions in the regional infrastructure. However, if for some companies, a purchase of a specific good is a production and technological necessity, then for the others it is as the principal type of activity. Therefore, accuracy in an evaluation of transaction costs might be only achieved at a level of relationships of each economic agent. Then, if at the same time, we take into account the entire variety of agents, we may say that there appears an effect of the intermediate consumption of transaction costs. It gets obvious that in the economic system, it is reasonable to use a consolidated value of all the transaction costs, except for a value of their intermediate consumption. In this case, a calculated residue of transaction costs serves as a tool to ensure continuity and a rhythm in an overall manufacturing process. A desired value of transaction costs at the infrastructure level in the economic system can be represented as follows:

$$
T C=\sum_{i=1}^{m} T C_{i}-I C
$$

where $T C$ - transaction costs in economic system; $I C$ - intermediate consumption of transaction costs; $m$ - number of companies in a particular economic system.

In terms of practice, a definition for intermediate consumption of transaction costs may be given using a system of national accounts and guidelines to calculate the gross domestic product or the gross regional product. As far as a calculation of the intermediate consumption of transaction costs is complex from a methodological point of view and as a specific index will be approximately the same value for each region, then it is possible to neglect a comparative analysis. Herewith, a quality of comparative assessments will not be subject to changes.

\subsection{Transactionalness as Performance Criterion for Regional Transport Infrastructure}

Across all regions in the regional economic system, each company has its own and distinct level of transaction costs. Maher (1997) indirectly mentioned this phenomenon, although the most essential finding from her research is an empirical evidence of a specific significance of the logistics infrastructure 
in the economic system in processes to define transaction costs. Popov adheres to the same logic and establishes a connection between the transactional function and parameters of the economic system host for a transaction.

We might briefly define a meaning of transactionalness with the "environment viscosity" term, where the environment refers to either a field of activity or a location of a production and commercial facility. Originally, Shevyakov and Kleiner (1993) introduced and used the term of "environment" to describe comparative terms to establish and launch production. In their work, they directly associate "environment viscosity" with uncertainty and risks, to which an economic agent will be subject. They say, "the higher environment viscosity is, the more difficult it is to send resources in a right direction and at a right time to fight against an adverse coincidence of events, and the higher degree of a risk is understood as a permanent environmental factor" (Kleiner, 1994).

In later works, Kleiner focuses on a descriptor of environmental viscosity defined as additional "significant, sometimes excessive efforts" (Kleiner, Tambovtsev \& Katchalov, 1997) in matters of resource handling to start manufacturing process. However, the most important remark relates to what predetermines environmental viscosity and to what extent it influences functioning of enterprises and organizations in the real sector of economy. Kleiner says that "viscosity of an economic environment does not only generate preconditions for inequality in functioning conditions of different sectors and regions, but also of separated but closely located enterprises in the same industry, makes it difficult to align living standards of the employees" (Ibidem, 26).

Taking into account that to describe "viscosity" of the environment, there have not been submitted any reasonable indicators so far, independent and not involved in a measurement of other parameters of a business system or an economic agent, therefore we believe that they are territorial and sectoral transactionalness that might become well-deserved indicative criteria to define a degree of the environment viscosity.

Herewith, companies in the same industry (activity) from various regions will not have the same individual volume of transaction costs. A difference will be in a strategic position and an acceptable risk, which companies have defined for themselves in the economic system. Thus, the introduced concept of "transactionalness" defines a cumulative effect of both external and internal conditions, which are in one or another way considered by persons, who make fundamental managerial decisions.

At the same time, with an evaluation of transactionalness, it is getting possible to justify a need of a region (area) in new or development of available transportation facilities. Then, say, the most infrastructure facilities established with the national government participation under projects of public-private partnerships are the very mechanism that helps to solve a challenge of a rational distribution of 
productive forces. The transactionalness value determines whether an industry (an economic activity) or a region as such is attractive (favourable) for an activity of an enterprise, a company or an organization. An economical meaning of the transactionalness index is essentially an assessment of a volume of unproductive costs attributed to a value of transformation (production) costs. Then, the production cost will represent transformation or production costs. However, the specific value of the transactionalness is much indicative in a calculation towards a value of revenue, as it represents an overall load.

As a result, an optimal form to calculate transactionalness by production is the following equation:

$$
T C E_{i}=\frac{T C_{i}}{P C_{i}} \text { and } T C E_{i} \%=\frac{T C_{i}}{P C_{i}} \times 100
$$

where $\mathrm{TCE}_{i}$ - transactionalness of the $\mathrm{i}^{\text {th }}{ }^{\text {th }}$ enterprise or entity; $P C_{i}$ - production cost; $\mathrm{TCE}_{i} \%$ transactionalness given in $\% \%$.

Taking equations (3) and (4) as a basis, we can estimate transactionalness in the transport infrastructure for the economic system of a national/regional level using the following formula:

$$
T C E=\frac{T C}{\sum_{i=1}^{m} P C-I C} \text { or } T C E=\frac{\sum_{i=1}^{m} T C_{i}-I C}{\sum_{i=1}^{m} P C-I C}
$$

where TCE - infrastructure transactionalness in national/regional economic system in absolute terms; $P C$ - consolidated value of production cost; $I C$ - value of intermediate consumption in relationships between economic agents in national/regional economics.

A logic in the author's approach comes from an assumption that a high value of transactionalness, in this case of areas with a relatively low development level of the transport infrastructure, reduces enterprise competitiveness and prevents an enterprise from sales with a higher benefit for themselves. That in turn causes numerous market risks for an enterprise. At the same time, it is not only crucial here to assess the transactionalness level of the transport infrastructure within the regional economic system, but also a pricing mechanism for specific goods or commodities. 


\section{Results and Discussion}

A transactionalness analysis for the regional transport infrastructure is made in a research of a number of indicators according to figures from consolidated data described in methodologies. These indicators include transactionalness by production cost and/or transactionalness by market revenue calculated in the framework of transport ARCEAs (All-Russian Classification of Economic Activities): (60) for the land transport activity, (61) for the water transport activity, (62) for the air and space transport activity and (63) for the support service and extra transport activity.

Calculations for the transactionalness index for the all-Russian transport infrastructure and the transactionalness index by types of transportation for 2005-2013 are given in Table 1.

\begin{tabular}{|l|c|c|c|c|c|c|c|c|c|c|}
\hline Transactionalness & & 2005 & 2006 & 2007 & 2008 & 2009 & 2010 & 2011 & 2012 & 2013 \\
\hline \multirow{3}{*}{ TI, including: } & I & 0.059 & 0.063 & 0.078 & 0.070 & 0.072 & 0.069 & 0.080 & 0.071 & 0.079 \\
\cline { 2 - 11 } & II & 0.068 & 0.073 & 0.092 & 0.081 & 0.083 & 0.080 & 0.093 & 0.081 & 0.090 \\
\hline \multirow{3}{*}{ (60) ARCEAs } & I & 0.047 & 0.050 & 0.064 & 0.056 & 0.058 & 0.057 & 0.070 & 0.065 & 0.070 \\
\cline { 2 - 11 }$y$ & II & 0.054 & 0.057 & 0.074 & 0.064 & 0.066 & 0.065 & 0.081 & 0.074 & 0.079 \\
\hline \multirow{3}{*}{ (61) ARCEAs } & I & 0.074 & 0.077 & 0.085 & 0.079 & 0.082 & 0.035 & 0.086 & 0.072 & 0.077 \\
\hline \multirow{3}{*}{ (62) ARCEAs } & II & 0.084 & 0.087 & 0.098 & 0.090 & 0.095 & 0.039 & 0.102 & 0.079 & 0.089 \\
\hline \multirow{2}{*}{ (63) ARCEAs } & I & 0.060 & 0.062 & 0.064 & 0.056 & 0.056 & 0.060 & 0.075 & 0.079 & 0.079 \\
\cline { 2 - 11 } & II & 0.065 & 0.068 & 0.071 & 0.059 & 0.061 & 0.067 & 0.082 & 0.087 & 0.087 \\
\hline \multirow{2}{*}{ Russia } & I & 0.096 & 0.101 & 0.128 & 0.115 & 0.123 & 0.115 & 0.104 & 0.080 & 0.097 \\
\cline { 2 - 10 }$y$ & II & 0.114 & 0.122 & 0.163 & 0.144 & 0.153 & 0.144 & 0.124 & 0.094 & 0.115 \\
\hline
\end{tabular}

Note. Calculated by the authors based on the baseline data provided by "Interfax" news agency on the SPARK Database. Estimated data are given in the collected book: Kuzmin, E.A., Dubrovsky, V.Zh. and Yaroshevich, N.Y., Transactionalness statistics for Russia (July 1, 2015). Available at SSRN: http://papers.ssrn.com/abstract=2699095

Table 1. Transactionalness in transport infrastructure (TI) as a whole and by activities in Russia for 2005-2013 (I - by market revenue / II - production cost)

Analysing the data from the table, one can trace a 2 points increase on the average for the transactionalness index in Russia in general (see details Appendix A) and transportation in 2013 compared to 2005. Therefore, transactionalness calculated in large for the transport infrastructure is as follows. Transactionalness by production cost increased by 2.2 percentage points, while transactionalness by revenue increased by $2 \mathrm{pp}$. This is slightly higher than a growth trend for the mentioned indicators as a whole by all lines of business (in 2013 against 2005, there was an increase by 1.3 percentage points and 1.2 percentage points respectively) across Russia. 
This discrepancy is associated with a higher share of transaction costs in costs of transportation providers due to specificity of assets and activities to provide services as such. At the same time, we should pay attention to the significant increase in a number of enterprises involved in the transport infrastructure. It was almost tripled, i.e. from 32,578 in 2005 to 93,644 in 2013. We should also mention a significant difference in an absolute value of transaction costs incurred by sub-sectors within the transport infrastructure.

Transaction costs of the land transport increased by $167 \%$ in 2013 compared to 2005 . The same value for other kinds of transportation was as follows. The water transport had $118.4 \%$, the air transport had 339\% and support service and extra vehicles had 146\%. Such a growth in an absolute value of transaction costs might relate to several trends. First, there is an active growth in transportation scopes of works (e.g. the air traffic in the same period increased by $280 \%$ ). Second, there were fewer stimuli to minimize and improve the performance of transportation providers.

Next, let us analyse transactionalness in the transport infrastructure broken down by federal districts, see Table 2.

\begin{tabular}{|c|c|c|c|c|c|c|c|c|c|}
\hline Region & 2005 & 2006 & 2007 & 2008 & 2009 & 2010 & 2011 & 2012 & 2013 \\
\hline Russia & 0.095 & 0.104 & 0.098 & 0.097 & 0.106 & 0.106 & 0.109 & 0.108 & 0.107 \\
\hline Central FD & 0.079 & 0.085 & 0.09 & 0.094 & 0.102 & 0.103 & 0.106 & 0.093 & 0.101 \\
\hline Southern FD & 0.074 & 0.078 & 0.086 & 0.089 & 0.110 & 0.097 & 0.107 & 0.101 & 0.099 \\
\hline Northwest FD & 0.096 & 0.960 & 0.103 & 0.105 & 0.124 & 0.116 & 0.151 & 0.131 & 0.123 \\
\hline Ural FD & 0.104 & 0.117 & 0.094 & 0.093 & 0.107 & 0.104 & 0.108 & 0.098 & 0.097 \\
\hline Siberian FD & 0.088 & 0.097 & 0.103 & 0.098 & 0.104 & 0.114 & 0.112 & 0.117 & 0.127 \\
\hline Far East FD & 0.094 & 0.106 & 0.103 & 0.099 & 0.107 & 0.103 & 0.105 & 0.098 & 0.094 \\
\hline Privolzhsky FD & 0.085 & 0.094 & 0.091 & 0.096 & 0.105 & 0.101 & 0.108 & 0.096 & 0.111 \\
\hline North-Caucasian FD & 0.070 & 0.081 & 0.065 & 0.092 & 0.102 & 0.099 & 0.077 & 0.097 & 0.079 \\
\hline
\end{tabular}

Note. Calculated by the authors based on the baseline data provided by "Interfax" news agency on the SPARK Database. Estimated data are given in the collected book: Kuzmin, E.A., Dubrovsky, V.Zh. and Yaroshevich, N.Y., Transactionalness statistics for Russia (July 1, 2015). Available at SSRN: http://papers.ssrn.com/abstract=2699095

Table 2. Transactionalness by revenue in regional transport infrastructures broken down by federal districts (FD) in 2005-2013, units

The highest values for transactionalness of the transport infrastructure are observed in the North-West and Siberian Federal Districts, a deviation from the Russian average value is about $20 \%$. The rest federal districts mainly comply with the all-Russian transactionalness index. 
Reviewing the transactionalness index dynamics by industries one can mention its increase by 1 pp. on the average. At the same time, the UFD does not follow this trend. If in 2005, the transactionalness value for the UFR exceeded the national index by 9 pp., then in 2013, it was as low as 10 pp. below the national value. Such trend can be explained with an increase in a quality of the regional transport infrastructure. Broken down by regions in the Ural Federal District, there is an analysis of transactionalness presented in Table 3.

\begin{tabular}{|c|c|c|c|c|c|c|c|c|c|}
\hline Region & 2005 & 2006 & 2007 & 2008 & 2009 & 2010 & 2011 & 2012 & 2013 \\
\hline Russia & 0.095 & 0.104 & 0.098 & 0.097 & 0.106 & 0.106 & 0.109 & 0.108 & 0.107 \\
\hline Ural FD & 0.104 & 0.117 & 0.094 & 0.093 & 0.107 & 0.104 & 0.108 & 0.098 & 0.097 \\
\hline Sverdlovsk Region & 0.078 & 0.095 & 0.094 & 0.093 & 0.088 & 0.092 & 0.095 & 0.075 & 0.087 \\
\hline Chelyabinsk Region & 0.075 & 0.083 & 0.088 & 0.075 & 0.090 & 0.082 & 0.076 & 0.070 & 0.080 \\
\hline Kurgan Region & 0.091 & 0.098 & 0.108 & 0.122 & 0.119 & 0.119 & 0.129 & 0.118 & 0.111 \\
\hline Tyumen Region & 0.170 & 0.193 & 0.087 & 0.084 & 0.134 & 0.125 & 0.132 & 0.128 & 0.110 \\
\hline
\end{tabular}

Note. Calculated by the authors based on the baseline data provided by "Interfax" news agency on the SPARK Database. Estimated data are given in the collected book: Kuzmin, E.A., Dubrovsky, V.Zh. and Yaroshevich, N.Y., Transactionalness statistics for Russia (July 1, 2015). Available at SSRN: http://papers.ssrn.com/abstract=2699095

Table 3. Transactionalness by revenue in regional transport infrastructures broken down by regions in the Urals Federal District in 2005-2013, units

Analysing the dynamics of changes to the transactionalness index by regions in the Urals Federal District, we should mention its high value for the Tyumen Region. Thus, a difference between the transactionalness indices for the transport infrastructure between the Tyumen Region and the Chelyabinsk Region is 9.5 pp. However, it should be also said that in 2005-2013, there was a $54 \%$ decrease in the transactionalness index for the Tyumen Region, which says of a less number of traffic limitations.

In general, the transactionalness index by regions of the Urals Federal District complies with the value of the national index. At the same time, the transactionalness index for the Sverdlovsk Region is usually 20\% lower than the national index, assuming relatively much more advanced technological and institutional environment, in which the transport infrastructure of the region exists.

It should be mentioned that today's practices to make a static analysis to assess the transport infrastructure development apply such indicator as a freight rate index. This index is to the most extent similar in its calculations to the transactionalness index as it uses a price of the cargo transportation, which includes the transaction costs among the others. 
This index represents a co-focus of a general trend revealed in the analysis, but cannot be used to its full extent to measure operational performance in the regional infrastructure due to a number of disadvantages. First, it only represents the dynamics of a price growth related to cargo transportation, i.e. a supply/demand ratio. At the same time, a low level of infrastructure development assumes limits to the supply and the demand, respectively. Second, it does not represent a qualitative and quantitative compliance of the transport infrastructure with the potential demand from commercial agents in the market. Thus, a higher level of regional infrastructure development represents a relatively low value of the growth dynamics for the freight rate index. The general dynamics of the rate index across the Sverdlovsk Region with respect to Russia as a whole was less than an exponent of 5.5\% in 2013 and 2014.

Thus, the proposed transactionalness index is much accurate, at least from the point of view that it makes the results of the regional transport infrastructure much completed and accurate.

The transactionalness analysis for region-wise and Russian national transport infrastructure has not disclosed its factor component, only being a static descriptor of an environment. There might be the following determinants for the transactionalness index dynamics in the transport infrastructure:

a) A level of an economic growth (recession) has an impact on a value of transactionalness. Under circumstances of an economic crisis, a demand for transport infrastructure services will decline; companies will minimize their costs, decreasing the index value, on the one hand. On the other hand, a crisis might encourage agents to search for new economical relationships and increase a level of transaction costs.

b) Geographic and economical position of a region. Its long mileage, difficult climatic conditions, on the one hand, and specifics in placement of major productive forces might increase or decrease a value of the index.

c) A level of technological development in the transport and logistical complex of a region. Use of modern technologies in transportation, a suitable number of available multi-transportation hubs with an appropriate quality that meet the specifics of economic development in a region are factors that decrease the transactionalness index. At the same time, retooling generates new or makes previously available institutional relationships within the environment much elaborated, which in turn increases a value of the index.

d) A level of competition in transport sectors. An establishment of a large number of transportation providers generates available artificial barriers at an entrance to the sector, while their overcoming requires other transaction costs as well as, to the equal extent, the increased concentration in the industry. 
e) An involvement of national government in ownership, management and control over the transport infrastructure. An increased government participation in relations with commercial parties in infrastructure sectors and an increasing number of administrative procedures cause a corresponding growth in transactionalness of the transport infrastructure.

f) A level of management efficiency and a quality of made decisions. A development of control systems, a use of marketing and logical control mechanisms in activities of a transportation provider result in both reduced transaction costs, and their growth at the same time.

It should be mentioned here that an impact of factors has a compensating action, e.g. stricter measures of government control might compensate for an increased competition. It is almost impossible to evaluate such action. Herewith, we might apply the transactionalness index as a static value that says of "environment viscosity" with certain thresholds. Thus, the transactionalness index let us describe the business environment. For the purposes of discussion, we can define this index as density of transaction costs that depend on a development level and performance of the transport infrastructure in a region.

\section{Conclusion}

The research has touched pressing issues in methodology of performance as an overall economic category drawing on the example of evaluated operating results for companies within the transport infrastructure. Meeting the goal set in the paper and critically summarizing traditional approaches, the authors assume a crucial role of transaction costs to determine a quality of the environment. Conclusions from the review of literature only go to confirm this. The case of the transport infrastructure is representative here, mostly in a search for opportunities to perform the fundamental system function, i.e. providing entities with necessary conditions for an efficient economic exchange. It becomes obvious that the known methods and concept are unable to resolve such a task.

The authors' attempt to solve the academic problem of a search for a cross functional criterion to assess a quality and a level of environment development, has embodied in the transactionalness index introduced for scientific use. Its meaning mostly comes down to several important trigger points, which have been determined. The main characteristic of transactionalness, on the one hand, is complexity of economical communication with a wider content implying implemented exchange processes. On the other hand, transactionalness is a condition of the institutional environment, therefore able to show relevant effects of uncertainty and risks. An analysis of its values dynamics can result in quite an objective estimate of changes to such a phenomenon for instance as a state of development in the regional transport infrastructure, considered in this paper as a research object to get an empirical evidence. Moreover, its region-wise national comparative analysis let us reveal weaknesses. Scientific consistency of assumptions 
made by the authors has been supported with the results from the approach piloted in the research on Russian companies in transport infrastructure in a region-wise review for 2005-2013.

It should be added here that the research of essential characteristics of the transaction costs has allowed making a number of important methodological conclusions. First, the transaction costs are made by an array of contractors and include both the costs to maintain a direct communication and a feedback between contractors, and the costs for formalization, i.e. for making a memory of these interactions. Secondly, there is their objective differentiation into those of the natural type and the background type. Developing their arguments, the authors have concluded that there are transaction costs in place, which are standard in a manner of speaking. All this serves as a starting point for the future and more detailed theoretical research on the transaction costs.

The approach proposed by the authors has some limitations in its applications. The transactionalness analysis for the transport infrastructure across regions and Russia as a whole does not disclose its component factor and is a static (torque) characteristic of the environment in time. There might be more factors determining the transactionalness dynamics for the transport infrastructure (e.g., level of technological development, government involvement, management quality. etc), but their significance is uncertain to the maximum extent. Herewith, in their combined impact, a number of factors is able to sett off the effect of each other. To smooth these contradictions, the authors' focus is the fact that the transactionalness index is cross functional.

\section{Acknowledgments}

This paper was prepared under research project No. 3026 "Improving government policy to develop competition in infrastructure sectors of economy with a natural monopoly component" according to a basic part of government commission given by the Ministry of Education and Science of the Russian Federation in a field of research No. 2014/238.

\section{References}

Arkhiereev, S.I. (2000). Transaction costs and inequalities in conditions of market transformation. Moscow: Business Inform.

Arrow, K. (1969). The organization of economic activity: issues pertinent to the choice of market versus non-market allocation. The Analysis and Evaluation of Public Expenditure: The PPB System, 1, 47-64. 
Auzan, A. (2006). Institutional economics: New institutional economics: course book. Moscow: INFRA-M, 51.

Balsevich, A.A., Yudkevich, M.M., \& Podkolzina, E.A. (2009). Transaction costs. Part 3: Priority national projects. Education. Moscow: GU VSHE Publishing House.

Burkov, A.L. (1999). Transaction costs as a criterion of performance in reforms of ownship relationships: academic papers. IE UB RAS.

Davidson, P. (2002). Financial markets, money, and the real world. Edward Elgar Publishing, 208. http://dx.doi.org/10.4337/9781843765585

Demchuk, A. (2002). Portfolio optimization with concave transaction costs. FAME Research Paper Series from International Centre for Financial Asset Management and Engineering: Research Paper, 103, 38. http://dx.doi.org/10.2139/ssm.481102

Eggertsson, T. (1990). Economic behaviour and institutions. Cambridge University Press. http://dx.doi.org/10.1017/CBO9780511609404

Gabriel, S.A., Mattey, J.P., \& Wascher, W.L. (2013). Compensating differentials and evolution in the quality-of-life among US states. Regional Science and Urban Economics, 33, 619-649.

http://dx.doi.org/10.1016/S0166-0462(02)00007-8

Harris L. (2003). Trading and exchanges: market microstructure for practitioners. Oxford University Press.

Haywood, R. (2012). Railways, urban development and town planning in Britain: 1948-2008. Ashgate Publishing.

Heinesen, E.A. (1992). Note on the simple two-variable CES transaction function in macroeconomic rationing models. No. 92-08, discussion papers. University of Copenhagen. Department of Economics.

Jabusch, D.M. (1985). Public speaking: a transactional approach. Allyn and Bacon.

Jinlong, Z. (2003). Test and analysis of the cozy extent of the overhead railway vehicles. Urban Mass Transit, 6(2), 46-51.

Jochimsen, R. (Ed.). (1966). Theorie der Infrastruktur, Grundlagen der marktwirtschaftlichen Entwicklung. Tübingen: JCB Mohr (Paul Siebeck).

Kleiner, G.B. (1994). Risks of industrial enterprises (how to reduce and offset them). Russian Journal of Economics, 5-6, 85-92.

Kleiner, G.B., Tambovtsev, V.L., \& Katchalov, R.M. (1997). Enterprise in unstable economic environment: risks, strategy, security. Moscow: Economics. 25. 
Kokorev, V. (1996). Institutional reforms in modern Russia: analysis of dynamics in transaction costs. Economics Affairs, 12, 61-87, 63, 66.

Krylov, P.M., \& Runova, T.G. (2008). Economic geography and regional studies: textbook. Moscow: MGIU.

Kuzmin, E. (2013). More theoretical and empirical studies of transaction costs in the economy: transactionalness in the Russian economy. Proceedings of the Saratov University. New series. Economy. Management. Law, 1, 13, 29-37.

Kuz'minov, I.Ya., Bendukidze, K.A., \& Yudkevich, M.M. (2006). Course of institutional economics: institutions, networks, transaction costs, contracts. Moscow: GU VSHE Publishing House.

Lahiri, K., \& Yao, W. (2004). A dynamic factor model of the coincident indicators for the US transportation sector. Applied Economics Letters, 11(10), 595-600.

http://dx.doi.org/10.1080/1350485042000271125

Lakshamanan, T.R. (2011). The broader economic consequences of transport infrastructure investments. Journal of Transport Geography, 19, 1-12. http://dx.doi.org/10.1016/j.jtrangeo.2010.01.001

Lipiec, Yu. G., Pulyarkin, V.A., \& Schlichter, S.B. (1999). Geography of world economics: course book. Moscow: VLADOS Hum. and Publ. Centre.

Maher, M.E. (1997). Transaction cost economics and contractual relations. Cambridge Journal of Economics, 21(2), 147-170. http://dx.doi.org/10.1093/oxfordjournals.cje.a013664

Milgrom, P.R., \& Roberts, J. (1992). Economics, organization, and management. Prentice-Hall.

Molle, W. (2004). Global economic institutions. Routledge, 213-236. http://dx.doi.org/10.4324/9780203356609

Murzaev, I.V. (2013). Regulation of cycles in regional infrastructure development in modern Russian economics. Cand. Sci (Econ.) thesis abstract. Kazan.

Nadiri, I.M. (1996). Constitution of highway capital to industry and national productivity. In Nadiri, I.M., \& Mamuneas, T.P. (Eds.). Final Report FHWA.

Popov, E.V. (2009). Transaction function: cooperation costs planning. Economy of Russia and Europe: Problems and Cooperation Prospects, 1(1), 1, 63-72.

Popov, E.V. (2011a). Transactions. Ekaterinburg: Ural Branch of Russian Academy of Sciences.

Popov, E.V. (2011b). Transactionalness in economic institutes of development. Bulletin of UrFU, Economics and Management Series, 4. 
Radaev, V.V. (1999). Russian business: structure of transaction costs. Social Studies and Present, 6, 5-19.

Ray, M.H., Weir, J.A., \& Hopp, J.A. (2003). In-service performance of traffic barriers. Transportation Research Board, 490.

Scherbinin, M.M. (2011). Management of transaction costs based on dynamic standard theory. In Musatova, N.A., \& Scherbinin, M.M. (Eds.). Innovative technologies in competitiveness management in area socio-economic systems: Proceedings of the $9^{\text {th }}$ All-Russian Conference of Young Researchers. Yekaterinburg: Institute of Economics of UB RAS, 104-111.

Serebryakov, F.A. (2007). Transaction costs in Russian economics: monograph. Moscow: RGUPS.

Sharon, J.E. (2014). Linking public capital to economic performance, public capital: the missing link between investment and economic growth. Economics Public Brief, 14. The Level Economics Institute.

Shastitko, A.E. (1997). Transaction costs (content, evaluation and correlation with transformation challenges). Economic Affairs, 7, 65-76.

Sheviakov, A., \& Kleiner, G. (1993). Socio-economic monitoring: concept, challenges and prospects. Economics and Mathematical Methods, 29(1), 5-14.

Stakhanov, V.N., \& Platonov, V.S. (1993). Market infrastructure: course book. Rostov-on-Don: RPNKHD Press.

Stigler, G. (1972). The law and economics of public policy: a plea to the scholars. Journal of Legal Studies, 1(1), 1-12. http://dx.doi.org/10.1086/467476

Syrov, M.V. (2008). Transaction costs of innovation process. Moscow: Publishing House of Moscow State Open University.

Thrall, G.I. (2002). Business geography and new real estate market analysis. Oxford University Press.

Voicu, A., \& Lahr, M.L. (2012). Creating a cost of doing business index. Working paper No. 141. New Jersey: Centre for Urban Policy Research, Rutgers University.

Wallis, J.J., \& North, D. (1986). Measuring the transaction sector in the American economy, 1870-1970. In Engerman, S.L., \& Gallman, R.E. (Eds.). Long-term factors in American economic growth. University of Chicago Press, 95-162, 96, 100.

Wing, L.S. (2007). The broader benefits of transportation infrastructure. In Wing, I.S., Anderson, W.P., \& Lakshamanan, T.R. Discussion Paper, 10. OECD, JTRC. 
Zhang, F. (2009). Economic analysis of Chinese transportation. CreateSpace Independent Publishing Platform.

\section{Appendix A}

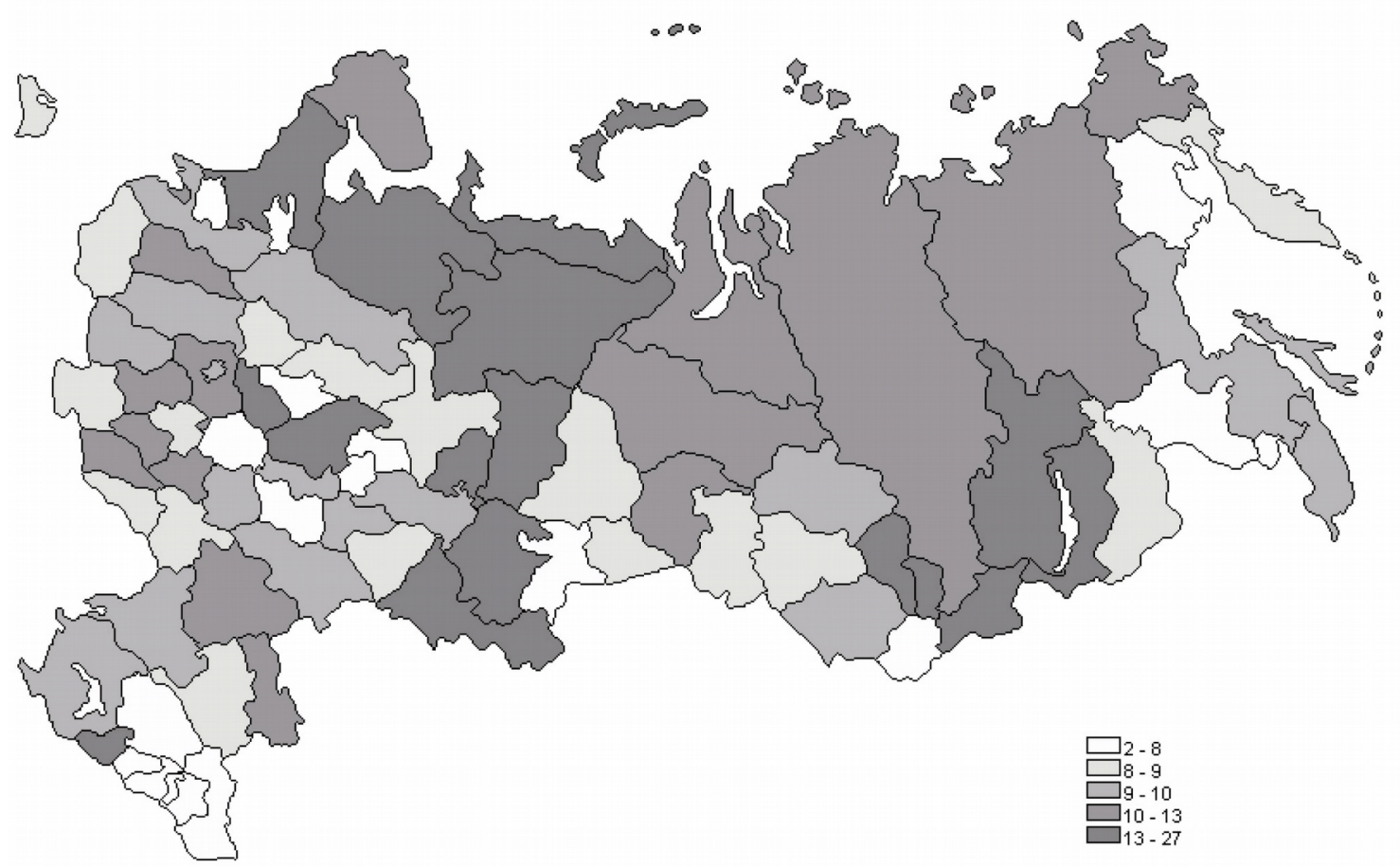

Note. Calculated by the authors based on the baseline data provided by "Interfax" news agency on the SPARK Database. Estimated data are given in the collected book: Kuzmin, E.A., Dubrovsky, V.Zh. and Yaroshevich, N.Y., Transactionalmess statistics for Russia (July 1, 2015). Available at SSRN: http://papers.ssrn.com/abstract=2699095

Figure A1. Transactionalness by revenue of Russian regions for 2013, units x 100 (equifilled matching)

Journal of Industrial Engineering and Management, 2016 (www.jiem.org)

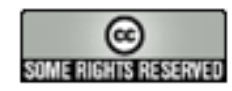

Article's contents are provided on an Attribution-Non Commercial 3.0 Creative commons license. Readers are allowed to copy, distribute and communicate article's contents, provided the author's and Journal of Industrial Engineering and Management's names are included. It must not be used for commercial purposes. To see the complete license contents, please visit http://creativecommons.org/licenses/by-nc/3.0/. 